\title{
O pensamento de Emilia Ferreiro sobre alfabetização
}

\author{
Márcia Cristina de Oliveira Mello
}

\begin{abstract}
RESUMO
Com o objetivo de contribuir para a compreensão de um importante momento da história da alfabetização no Brasil, analisam-se aspectos do pensamento da pesquisadora Emilia Ferreiro (1937 - ） sobre alfabetização, com ênfase em suas concepções a respeito do processo de construção do conhecimento da língua escrita, por parte de crianças, que resultam de sua pesquisa sobre a psicogênese da língua escrita, fundamentada na Epistemologia Genética de Jean Piaget e na Psicolingüística de Noam Chomsky, e que tiveram significativa repercussão em nosso país, a partir de meados dos anos de 1980. O tema é abordado de uma perspectiva histórica, por meio da utilização de procedimentos de localização, reunião e ordenação da bibliografia disponível de e sobre. Emilia Ferreiro e da análise da configuração textual do livro Psicogênese dà língua escrita.

Palavras-chave: alfabetização, construtivismo, educação, Brasil, Emilia Ferreiro, história da alfabetização.

\section{Título em inglês: THE OPINION OF EMILIA FERREIRO WITH REGARDS TO LITERACY}

\section{ABSTRACT}

With the aim of contributing for the comprehension of an important moment of literacy history in Brazil, Emilia Ferreiro's (1937 _ _ ) literacy thoughts aspects are analyzed, emphasizing her conceptions about the process of construction of the written system by children, which result from her research on psychogenesis of the written language, based on Jean Piaget's Epistemological Genetic and on Noam Chamsky' Psycholinguistic which had significant repercussion in our country in early $80 \mathrm{~s}$. The theme is encircled on a historical perspective, throughout the use of placement-procedures, gathering and available bibliography classification by and about Emilia Ferreiro and the analysis of the textual shape of the book Psicegênese da lingua escrita.
\end{abstract} history.

Index Terms: constructivism, education, Brazil, Emilia Ferreiro, literacy, literacy

\section{O Pensamento de Emilia Ferreiro sobre alfabetização}

Nos anos de 1980 são divulgados, no Brasil, os resultados dos estudos realizados pela pesquisadora argentina, Emilia Ferreiro, e seus colaboradores, contendo uma nova abordagem do processo de aquisição da língua escrita pela criança. 
No caso brasileiro, essa nova abordagem passou a ser conhecida como "construtivista" e se tornou a principal referência teórica do discurso educacional relacionado com alfabetização (MORTATTI, 2000). Dada a importância do pensamento dessa pesquisadora, é preciso compreendê-lo de um ponto de vista histórico: qual o seu significado, o que representou e o que representa para a história da alfabetização no Brasil?

Motivada em conhecer aspectos da história da alfabetização no Brasil, desenvolvi pesquisas documental e bibliográfica, vinculadas ao Grupo de Pesquisa "História do ensino de língua e literatura no Brasil" (GPHELLB) e ao Projeto Integrado de Pesquisa "Ensino de língua e literatura no Brasil: repertório documental republicano" (PIPELLB) ${ }^{1}$, ambos coordenados por Maria do Rosário Longo Mortatti e subdivididos em cinco linhas de pesquisa, dentre as quais, Alfabetização, entendida como ensino de leitura e escrita na fase inicial de escolarização de crianças ${ }^{2}$.

Para tanto, elaborei, inicialmente, um instrumento de pesquisa, no qual se encontram reunidas e organizadas, além de dados biográficos sobre a pesquisadora, 127 referências bibliográficas de textos escritos por essa pesquisadora e traduzidos para diversos idiomas, entre 1969 (ano de publicação de seu primeiro artigo em francês) e 2002 (ano de encerramento de minha pesquisa documental), e oito referências de textơs relacionados ao pensamento construtivista de Emilia Ferreiro sobre alfabetização ${ }^{3}$, produzidos no Brasil, entre 1990 (ano de defesa da primeira dissertação sobre o tema) e 1999 (ano de publicação do último livro localizado).

Esse instrumento de pesquisa propiciou constatar que Emilia Ferreiro possui uma vasta produção escrita, traduzida para diversos idiomas, em vários países, dentre-eles o Brasil. Foi possível constatar, também, que são poucos os estudos e as pesquisas realizadas sobre o pensamento construtivista de Emilia Ferreiro no tocante à alfabetização. Até o final das pesquisas documental e bibliográfica foi possível localizar apenas oito referências bibliográficas de textos que tratam do pensamento construtivista de Emilia Ferreiro sobre alfabetização, não tendo sido localizado nenhum que aborde especificamente a produção de Emilia Ferreiro e seu pensamento construtivista sobre alfabetização, sob uma perspectiva histórica. O que se encontram são textos que trazem propostas de aplicação,

\footnotetext{
${ }^{1}$ Esse projeto foi desenvolvido entre agosto de 1999 e julho de 2003 e recebeu apoio e auxílio financeiro do CNPq e auxílio financeiro da FAPESP.

${ }^{2}$ As cinco linhas de pesquisas em que se subdividem o GPHELLB e o PIPELLB são: 1. Formação de professores de língua e literatura (inclusive alfabetizadores). 2. Alfabetização. 3. Ensino da Língua Portuguesa. 4. Ensino de Literatura. 5. Literatura Infantil e Juvenil.

${ }^{3}$ Quando utilizo a expressão "bibliografia relacionada ao pensamento construtivista de Emilia Ferreiro sobre alfabetização" refiro-me aos textos em forma de livros, dissertações e tese em que se analisam aspectos do pensamento, da atuação profissional e da obra de Emilia Ferreiro. A bibliografia completa encontra-se em Mello (2003).
} 
em sala de aula, das idéias de Emilia Ferreiro e colaboradores, o que não é a proposta da pesquisa, cujos resultados apresento.

Essas constatações fizeram-me confirmar meu interesse de pesquisa inicial e eleger como corpus para análise o livro Psicogênese da língua escrita, escrito por Emilia Ferreiro e Ana Teberosky, traduzido, no Brasil, em 1985.

O critério para a escolha desse livro relaciona-se com os seguintes aspectos: foi o primeiro livro de Ferreiro traduzido no Brasil; nele são apresentados os resultados da pesquisa sobre a psicogênese da língua escrita, realizada por Emilia Ferreiro e colaboradores, os quais não foram ainda radicalmente contestados; apenas, por vezes, criticados. Talvez por essa razão, trata-se de um livro pouco lido, considerando-se as tiragens, comparativamente com outros títulos da autora.

Analisando o conjunto da obra da pesquisadora traduzida e publicada no Brasil, identifiquei no livro escolhido características que me permitem considerá-lo um marco do pensamento construtivista de Emilia Ferreiro sobre alfabetização. Vale ressaltar que, embora tendo sido escrito em co-autoria com Ana Teberosky, ficou conhecido no Brasil como "O livro de Emilia Ferreiro", e as idéias nele contidas ficaram conhecidas como o "construtivismo de Emilia Ferreiro", devido ao fato de a imagem da pesquisadora ter ganhado proeminência, desde seus primeiros contatos com educadores de nosso país.

A partir de meados da década de 1980, os resultados da pesquisa sobre a psicogênese da língua escrita, desenvolvida por Emilia Ferreiro e colaboradores, enfeixados sob a denominação "construtivismo", foram considerados referencial teórico, por exemplo, no estado de São Paulo, para o Ciclo Básico de Alfabetização (CBA)

Daquela época até os dias de hoje, as idéias dessa pesquisadora esfão presentes no discurso brasileiro sobre alfabetizaçâo, seja em documentos institucionais, em artigos de revistas especializadas, em textos de anais de congressos, em textos sugeridos aos professores para utilizarem em sua prática pedagógica as idéias de Emilia Ferreiro, seja, ainda, em livros, teses e dissertações acadêmicas sobre alfabetização.

Emilia Ferreiro ganhou prestígio por desenvolver, com seus colaboradores, pesquisa empírica que lhe permitiu formular a teoria sobre a psicogênese da língua escrita, a qual foi divulgada em diversos países, dentre eles, o Brasil. Sua atuação profissional revela, também, o compromisso político em contribuir na busca de soluções para se enfrentar o problema do analfabetismo.

Essa busca de soluções, tendo em vista a modificação da realidade educacional dos países da América Latina, em relação ao fracasso na alfabetização, principalmente das 
crianças das classes sociais menos favorecidas, levou Ferreiro a propor, por meio, especialmente, dos resultados da pesquisa contidos no livro Psicogênese da língua escrita, uma nova maneira de se pensar a alfabetização, já que, para a pesquisadora, o fracasso na alfabetização está relacionado à maneira pela qual esse processo vinha sendo proposto e praticado até então.

Ante essas considerações, Ferreiro afirma ter feito uma "revolução conceitual" a respeito da alfabetização, por ter "mudado" o eixo em torno do qual passavam as discussões sobre o tema: dos debates sobre os métodos e os testes utilizados para o ensino da leitura e da escrita para a idéia de que não são os métodos que alfabetizam, nem os testes que auxiliam o processo de alfabetização, mas são as crianças que (re)constroem o conhecimento sobre a língua escrita, por meio de hipóteses que formulam, para compreenderem o funcionamento desse objeto de conhecimento.

Além dessa proposta de "mudança de olhar" sobre o processo de alfabetização, a "revolução conceitual" proposta está, também, relacionada com a própria concepção de língua escrita e de alfabetização. Para a pesquisadora, a língua escrita deve ser entendida como um sistema de representação da linguagem, concepção que se opõe àquela em que a língua escrita é considerada como codificação e decodificação da linguagem.

Conseqüentemente, Ferreiro se opõe ao conceito de alfabetização entendido como a aprendizagem de duas técnicas diferentes (codificar e decodificar a língua escrita), em que o professor é o único informante autorizado. Ferreiro defende, então, o conceito de alfabetização que vai em sentido contrário, já que a considera como o processo 'de aprendizagem da língua escrita. Essa aprendizagem, considerada, também, "aprendizagem conceitual", dá-se por meio da interação entre o objeto de conhecimento (aلlíngua escrita) e o sujeito cognoscente (que quer conhecer).

Desde o início da divulgação do pensamento construtivista de Emilia Ferreiro sobre alfabetização em nosso país, em meados dos anos de 1980, as tensões decorrentes da apropriação desse pensamento no âmbito de propostas oficiais estavam relacionadas com as discussões sobre o significado da "revolução conceitual" proposta por Emilia Ferreiro. Embora essa tensão pareça ter-se amenizado e embora não se tenham notícias de que os resultados da pesquisa de Ferreiro e colaboradores tenham sido refutados em seus fundamentos e resultados, vêm sendo apresentadas muitas críticas, relacionadas, sobretudo, com a dúvida a respeito do papel do ensino, da escola e do professor, a partir desse ponto de vista. 
Tais dúvidas estão relacionadas com o fato de que no livro Psicogênese da língua escrita não se encontra uma proposta didática de alfabetização, nem "receitas prontas" com intenção de garantir o sucesso da alfabetização de todas as crianças em fase inicial de escolarização ${ }^{4}$.

Nesse livro, são encontrados resultados de pesquisa acerca do processo de aquisição da língua escrita por parte de crianças, os quais podem contribuir para a compreensão do modo pelo qual esse processo complexo acontece. Tal compreensão é importante, sobretudo, para professores e psicólogos, público a que se destina preferencialmente o livro.

Para os professores, o livro pode auxiliar na interpretação das respostas dadas pelas crianças, quando estas estão produzindo ou interpretando textos, para levar essas respostas em consideração durante o processó de construção, pela criança, do conhecimento da língua escrita. As autoras entendem que, fornecendo essas informações aos professofes, elas estão contribuindo para diminuir o número daqueles que fracassam nessa etapa de escolarização.

Para os psicólogos, a obra fornece elementos que permitem compreender o que ocorre durante o processo de aquisição da língua escrita, os quais, segundo as autorảs, auxiliam o trabalho desses profissionais, porque, quando lidam com crianças, geralmente aquelas que fracassam no início do processo de alfabetização, eles não têm conhecimentos desse processo, podendo considerar as interpretações das crianças como índices de futuros transtornos ou como casos patológicos.

Levando-se em consideração as principais características do livro - apresentação de uma teoria contendo "novas" interpretações sobre o processo de aprendizagem da leitura e da escrita, resultado de uma pesquisa descrita minuciosamente, em um número elevado de páginas - , pode-se concluir que sua leitura não é de simples compreensão, porque envolve outras teorias que a embasam, demandando, por parte do leitor, certa familiaridade, sobretudo, com os fundamentos da teoria piagetiana e da Psicolinguíística chomskyana. Essas características talvez expliquem, também, a relativamente baixa tiragem do livro no Brasil, comparativamente à intensa e extensa divulgação do pensamento construtivista de Emilia Ferreiro sobre alfabetização no país.

No entanto, embora as idéias contidas nesse volume tenham sido e continuem sendo muito divulgadas, por meio tanto das apropriações que se fizeram e se fazem desse pensamento, por parte do "discurso oficial", quanto dos estudos e pesquisas acadêmicas a

\footnotetext{
${ }^{4}$ Dentre os pesquisadores que tratam do assunto destaco: Azenha (1993) e Ribeiro (1991).
} 
esse respeito, são poucos aqueles que "dominam" o pensamento construtivista de Emilia Ferreiro sobre alfabetização. Podemos supor que entre esses poucos leitores estão especialistas em alfabetização, equipes pedagógicas de órgãos oficiais, pesquisadores do meio acadêmico e alguns poucos professores alfabetizadores.

A análise de Psicogênese da língua escrita propiciou confirmar sua relevância no que se refere à compreensão do pensamento construtivista de Emilia Ferreiro sobre alfabetização. Essa importância deriva justamente do fato de nele estar contida o que denomino "matriz invariante" desse pensamento, considerado pelas autoras do livro, como já mencionei, e por outros pesquisadores, uma "revolução conceitual" em alfabetização.

Trata-se de matriz, porque é entendida como atributo principal, e é invariante, porque, posteriormente, vai-se expandindo, mas sempre preservando suas características fundamentais, as quais lhe conferem unidade e continuidade.

Essa unidade está relacionada com as influências tanto da Epistemologia Genéfica de Piaget quanto da Psicolinguiística de Chomsky, que constituem um núcleo comum de ancoragem da teoria sobre a psicogênese da língua escrita. Nesse sentido, o prineípal atributo da matriz invariante do pensamento construtivista de Emilia Ferreiro sobre alfabetização consiste no fato de essa pesquisadora considerar que a atividade estruturante do sujeito faz com que ele construa esquemas interpretativos para compreender a natureza da escrita.

As características fundamentais dessa matriz, por sua vez, consistem na constatação de que as crianças possuem capacidades cognitivas (capacidades de desenvolver raciocínios) e lingüísticas (capacidades de desenvolver concepções sobre o sistema de escrita), utilizando-as para entender o mecanismo de funcionamento da língua escrita no processo $\mathrm{de}$ aprendizagem da leitura e da escrita. Nesse processo, as crianças (re)constroem o conhecimento sobre a língua escrita, por meio de uma elaboração pessoal, a qual se dá por sucessão de etapas, cada uma delas representando um estágio importante do processo. Assim, a interpretação do processo é explicada do ponto de vista das crianças que aprendem, levando-se em consideração o conhecimento específico que possuem antes de iniciar a aprendizagem escolar, a saber: a escrita não representa apenas um traço ou marca, mas sim "um objeto substituto".

Partindo desse conhecimento, as crianças seguem uma linha de evolução regular até a aquisição da língua escrita, elaborando hipóteses para compreender o funcionamento do código escrito. 
O conjunto das hipóteses elaboradas pelas crianças, denominado de "níveis de conceitualização", pode ser minimamente categorizado em: "distinção entre o icônico e não-icônico"; "exigência de quantidade mínima e variedade de caracteres"; "hipótese silábica"; "hipótese silábica-alfabética"; e "hipótese alfabética". Do início ao fim desse processo ocorre um processo de (re)construção do conhecimento da língua escrita, o qual se dá por meio da interação das crianças com o objeto de conhecimento.

Nos textos escritos posteriormente por Ferreiro, observa-se que a pesquisadora vai expandindo essa matriz de seu pensamento. Neles, a pesquisadora amplia e aprofunda as primeiras formulações sobre a teoria da psicogênese da língua escrita, conciliando relatos de situações e resultados de investigações desenvolvidas sobre a aprendizagem da língua escrita, seja por parte de crianças, seja por parte de adultos, seja por parte de povos indígenas.

Entre essas pesquisas estão também as comparativas, desenvolvidas com crianças inseridas em diferentes contextos lingüísticos, como, por exemplo, entre português, italiano e espanhol, nas quais a pesquisadora destaca as semelhanças e as diferenças no desenvolvimento psicogenético dessas crianças.

Ampliando essa temática, a pesquisadora aborda, em seus textos posteriorés, assuntos atuais, como a entrada das novas tecnologias (computadores e internet) nas escolas e a discussão em torno do "letramento", confirmando sua contemporaneidade em relação ao discurso sobre alfabetização. No entanto, em tudo o que escreve, aquela matriz invariante está sempre presente.

Pelo exposto, pode-se concluir que Psicogênese da língua escrita tornou-se-um marco na produção intelectual de Ferreiro e no que se refere ao seu pensamento construtivista sobre alfabetização. É importante ressaltar que, embora esse livro tenha sido escrito em co-autoria com Ana Teberosky ${ }^{5}$, a maior parte da vasta produção escrita de Ferreiro, é de autoria de Ferreiro e não está vinculada exclusivamente à de Teberosky; nem tampouco a de outros pesquisadores, com os quais Ferreiro assina algumas outras publicações.

Por fim, vale enfatizar que, depois das tensões iniciais decorrentes da divulgação desse pensamento - cuja matriz invariante se encontra no livro analisado - e dos

\footnotetext{
${ }^{5}$ Ana Teberosky atualmente desenvolve sua atividade profissional como docente do Departamento de Psicologia Evolutiva e da Educação da Universidade de Barcelona, na Espanha, onde desenvolveu pesquisas na área da linguagem junto ao Instituto Municipal de Investigações Psicológicas Aplicadas à Educação (IMIPAE) e ao Instituto Municipal de Educação (IME). No Brasil outros textos de Ana Teberosky foram traduzidos e publicados, como, por exemplo, Psicopedagogia da linguagem escrita (1990), em que a pesquisadora apresenta uma proposta pedagógica de alfabetização por meio da utilização de diferentes tipos de textos, inversamente do que faz Ferreiro, que em seus textos não encaminha propostas pedagógicas.
} 
questionamentos por alguns estudiosos do assunto, ele permanece atuante, até os dias de hoje, nos discursos e nas práticas de alfabetização no Brasil. Porém, o pensamento de Ferreiro gerou, por meio de suas apropriações, "revolução" no "fazer" a alfabetização em São Paulo e no Brasil? Penso que, mais do que antes, esse é um assunto para ser debatido.

\section{Referências bibliográficas}

AZENHA, Maria da Graça (1993). Construtivismo: de Piaget a Emilia Ferreiro. São Paulo: Ática.

FERREIRO, Emilia; TEBEROSKY, Ana (1985). Psicogênese da língua escrita. Tradução de Diana M. Linchestein et al. Porte Alegre: Artes Médicas.

MELLO, Márcia Cristina de Oliveira. Um estudo sobre o pensamento construtivista de Emilia Ferreiro sobre alfabetização. Marília, 2003. 175 f. Dissertação (Mestrado elm Educação). Universidade Estadual Paulista de Marília.

MORTATTI, Maria do Rosário Longo (2000). Os sentidos da alfabetização: São Paulo1876/1994. São Paulo: UNESP; Brasília: MEC, INEP, COMPED.

RIBEIRO, Vera Masagão. Problemas da abordagem piagetiana em educação: Emilia Ferreiro e a alfabetização. São Paulo, 1991. 109 f. Dissertação (Mestrado em Filosofià da Educação). Pontifícia Universidade Católica de São Paulo.

TEBEROSKY, Ana (1990). Psicopedagogia da linguagem escrita. Tradução de Beatriz Cardoso. 3. ed. São Paulo: Trajetória Cultural.

\section{Autora}

\section{Márcia Cristina de Oliveira MELLO}

Doutoranda em Educação na Universidade Estadual de São Paulo (UNESP)/Marília Telefones: (14) 3326-7324 - (14) 8127-4399

Rua Manoel da Silva Mano, 670 - Ourinhos/SP - 19906-510

marciacomello@ig.com.br

\section{Como citar este artigo:}

MELLO, Márcia Cristina de Oliveira. O pensamento de Emilia Ferreiro sobre alfabetização. Revista Moçambras: acolhendo a alfabetização nos países de língua portuguesa, São Paulo, ano 1, n. 2, 2007. Disponível em: 〈http://www.mocambras.org>. Publicado em: março 2007. 